\title{
Cytoplasmic polyadenylation controls cdc25B mRNA translation in rat oocytes resuming meiosis
}

\author{
Eran Gershon, Dalia Galiani and Nava Dekel \\ Department of Biological Regulation, The Weizmann Institute of Science, Rehovot, 76100, Israel \\ Correspondence should be addressed to N Dekel; Email: nava.dekel@weizmann.ac.il
}

\begin{abstract}
Resumption of meiosis in oocytes represents the entry into M-phase of the cell cycle and is regulated by the maturation-promoting factor (MPF). Activation of MPF is catalyzed by the dual specificity phosphatase, cdc25. In mammals, cdc25 is represented by a multigene family consisting of three isoforms: A, B and C. A recent report that female mice lacking cdc25B exhibit impaired fertility suggests a role for this isoform in regulating the G2- to M-transition in mammalian oocytes. Supporting the abovementioned observation, we demonstrate herein that microinjection of neutralizing antibodies against cdc25B interfered with the ability of rat oocytes to undergo germinal vesicle breakdown (GVB). We also show accumulation of cdc25B in GVB oocytes and a transient reduction in its amount at metaphase I of meiosis. The accumulation of cdc25B was associated with its mRNA cytoplasmatic polyadenylation and was prevented by the protein synthesis inhibitor cyclohexamide as well as by the polyadenylation inhibitor cordycepin. Immunofluorescence staining revealed translocation of cdc25B to the metaphase II spindle apparatus. Taken together, our findings provide evidence that cdc25B is involved in resumption of meiosis in rat oocytes. We further demonstrate for the first time, a periodic accumulation of cdc25B throughout meiosis that is translationally regulated and involves cdc25B mRNA polyadenylation.

Reproduction (2006) 132 21-31
\end{abstract}

\section{Introduction}

Meiosis is a particular example of cell division occurring in germ cells. The entry of the female germ cell into meiosis takes place in the fetal ovary. The meiotic division in oocytes proceeds up to the diplotene stage of the first prophase and is arrested around birth. The oocytes arrest at a stage that corresponds to the G2-phase of the cell cycle and are characterized by diffuse chromosomes surrounded by a nuclear membrane known as germinal vesicle (GV). Reinitiation of meiosis takes place in sexually mature females and is triggered in vertebrates by the pituitary gonadotropin, leutenizing hormone (LH). Mammalian oocytes can also resume meiosis spontaneously, upon their removal from the ovarian follicle (reviewed by Tsafriri \& Dekel 1994). Reinitiation of meiosis represents the transition from G2to M-phase of the cell cycle and involves dissolution of the nuclear membrane referred to as germinal vesicle breakdown (GVB), chromosome condensation, formation of the spindle of the first metaphase (MI), and segregation of the homologous chromosomes. Oocytes complete the first meiotic division by the formation of the first polar body (PBI) that is immediately followed by their maturation into unfertilized eggs arrested at the second metaphase of meiosis (MII). Completion of the second meiotic division is triggered at fertilization by sperm penetration (reviewed by Dekel 1996).

The key regulator of meiosis is the maturationpromoting factor (MPF) (Masui \& Markert 1971), which consists the catalytic p34cdc2 serine/threonine kinase and the regulatory cyclin B (Gautier et al. 1988, 1990). Activation of MPF is initially dependent on the availability of cyclin $B$ that allows the formation of the p34cd2/cyclin B complex, known as pre-MPF. This preMPF stays inactive under the influence of the wee- 1 and myt-1 kinases that phosphorylate the threonine 14 and tyrosine 15 residues of p34cdc2 (Russell \& Nurse 1986, Gould \& Nurse 1989, Mueller et al. 1995, Booher et al. 1997). The dual specificity phosphatase cdc25, which removes these inhibitory phosphates, converts the inactive pre-MPF into an active MPF (Gautier et al. 1991, Kumagai \& Dunphy 1991, Millar et al. 1991, Strausfeld et al. 1991, Sebastian et al. 1993).

Homologs of cdc25 have been identified in different organisms including yeasts (Russell \& Nurse 1986, Russell et al. 1989), Caenorhabditis elegans (Ashcroft et al. 1998), Drosophila (Edgar \& O'Farrell 1989, 
Alphey et al. 1992, Courtot et al. 1992), and Xenopus (Izumi et al. 1992, Kumagai \& Dunphy 1992). Mitosis in fission yeast is regulated by the rate of accumulation of cdc25 during G2 (Russell \& Nurse 1986). On the other hand, the amount of cdc25 in Xenopus oocytes is constant and its activity is regulated posttranslationally by multiple phosphorylations. Phosphorylation of cdc25 is catalyzed by members of the polo-like family of kinases (Kumagai \& Dunphy 1996, Qian et al. 1998) as well as by p34cdc2 kinase. The reciprocal phosphorylation of cdc25 and MPF creates an autocatalytic loop that sustains the activities of these two enzymes to drive the cell cycle into M-phase (Izumi et al. 1992, Kumagai \& Dunphy 1992, Hoffmann et al. 1993). Conversely, phosphatase $2 \mathrm{~A}$ is proposed to be involved in a negative regulation of cdc25 activity (Kumagai \& Dunphy 1992, Clarke et al. 1993, Hoffmann et al. 1993).

Another mechanism that participates in regulation of cdc25 action involves alteration of its cellular distribution. Localization of cdc25 is determined by the 14-3-3 protein (Conklin et al. 1995, Furnari et al. 1997, Peng et al. 1997, Dalal et al. 1999, Kumagai \& Dunphy 1999) that binds the phosphatase and prevents its transport into the nucleus (Zeng \& Piwnica-Worms 1999, Davezac et al. 2000).

In mammalian cells, cdc25 represents a multigene family consisting of A, B, and C isoforms (Galaktionov \& Beach 1991, Nagata et al. 1991, Jinno et al. 1994). Each member of the mammalian cdc25 family has a role at a particular phase of the cell cycle that is determined by its substrate specificity (Sebastian et al. 1993). Accordingly, cdc25A regulates the $\mathrm{G} 1$ - to S-phase transition, by dephosphorylating the Cdk2-cyclin E kinase (Hoffmann et al. 1994, Jinno et al. 1994), whereas the entry into mitosis is regulated by cdc25C (Sadhu et al. 1990, Millar et al. 1991), which elicits its action towards the p34cdc2/ cyclin B complex (Gautier et al. 1991). Evidence regarding the role of cdc25B is still controversial. One report proposed that this form of cdc25 is required for progression into S-phase (Garner-Hamrick \& Fisher 1998), while other studies have shown that cdc25B has a role in the G2-phase as a regulator of centrosomal microtubule nucleation (Millar et al. 1991, Gabrielli et al. 1996) and a starter of mitosis (Nishijima et al. 1997). This controversy can be possibly explained by the discovery of at least three splice variants of cdc25B that display differences in their biochemical properties (Baldin et al. 1997b).

A large body of information on the role of cdc25 in meiosis has been generated in Xenopus oocytes with hardly any available data on this key phosphatase in mammals. Furthermore, the specific member of the mammalian cdc25 family that functions in meiosis of mammalian oocytes is largely unknown. Early studies detected mRNA of cdc25B in murine ovaries particularly in oocytes, while mRNAs of cdc25A and cdc25C were observed in spermatids (Wickramasinghe et al. 1995,
Wu \& Wolgemuth 1995). Conflicting results were reported by a later study that identified cdc25C mRNA in mouse oocytes further demonstrating an increase in its protein product during oocyte maturation (Mitra \& Schultz 1996). Along this line, it has been shown that cdc25C is essential for progression of porcine oocytes through late diakinesis and that de novo synthesis of this isoform is required for the transition from meiosis in oocytes to mitosis in early embryos (Dai et al. 2000). However, normal fertility exhibited by cdc25C deficient female mice (Chen et al. 2001) suggests that this phosphatase is either irrelevant or that another protein compensates for its function in the control of meiosis. A more recent report indeed demonstrated that oocytes of mice lacking cdc25B fail to activate MPF and remain meiotically arrested (Lincoln et al. 2002). Taking this information into account, we examined the pattern of cdc25B expression and investigated the mode of its regulation in rat oocytes resuming meiosis.

Supporting the above-mentioned observations, we show that microinjection of neutralizing antibodies against cdc25B, but not cdc25C impaired the ability of oocytes to resume meiosis. Along this line, we demonstrate changes in cdc25B localization that are associated with the progress of meiosis. Our findings also reveal that cdc25B exhibits periodic accumulation throughout meiosis that is translationally regulated and corresponds to the oscillatory pattern of MPF activation. We show herein that cdc25B translation is mediated by polyadenylation of its mRNA.

\section{Materials and Methods}

\section{Animals}

Eighteen (weighing around $30 \mathrm{~g}$ ) or 25-day-old (weighing around $60 \mathrm{~g}$ ) female Wistar rats were purchased from Harlan Laboratories (Rehovot, Israel). Animals were housed under constant conditions of temperature and humidity, with lights on between 0600 and $2000 \mathrm{~h}$, and food and water available ad libitum.

The investigation was conducted in accordance with the Guide for the Care and Use of Laboratory Animals (National Research Council, National Academy of Science; Bethesda, MD, USA).

\section{Antibodies and reagents}

Cyclohexamid (CHX), isobutylmethylxanthine (IBMX), leupeptin, cordycepin and dibutyryl-cAMP (dbcAMP) were purchased from Sigma. MG132 (Z-leu-leu-CHO) was purchased from Calbiochem (Schwalbach, Germany). Syto13 was purchased from Molecular Probes (Paisley, Strathclyde UK). Goat anti-mouse-HRP, goat anti-rabbit-HRP and goat anti-mouse-Cy3 were purchased from Jackson Laboratories (West Grove, PA, USA). Monoclonal mouse anti-cdc25B antibodies were 
purchased from Transduction Laboratories (San Jose CA USA). The cdc25B peptide was purchased from Transduction Laboratories; this peptide includes the amino acids in the 109-122 position of cdc25B protein sequence. Polyclonal rabbit anti-p34cdc2 antibodies were purchased from Santa Cruz (Santa Cruz CA, USA). Monoclonal mouse anti-tubulin antibody was purchased from Sigma.

\section{Oocytes recovery and culture}

Rat oocytes that resume meiosis spontaneously upon their removal from the ovarian follicles were employed for our study. The ability to resume meiosis is acquired progressively during oocyte growth. Accordingly, oocytes that are incompetent and competent to resume meiosis are referred to as growing and fully grown, respectively. A previous study in our laboratory (Goren \& Dekel 1994) demonstrated that ovaries of 18-day-old Wistar rats contain growing oocytes, while fully grown oocytes can be recovered from ovaries of 25-day-old rats, primed ( $48 \mathrm{~h}$ earlier) with $10 \mathrm{IU}$ of pregnant mare's serum gonadotropin (PMSG, Chrono-gest Intervest). These two groups of animals served, therefore, as the source for the oocytes used for this study. The rats (Harlan, Rehovot, Israel) were sacrificed and their ovaries isolated and transferred into Leibovitz L-15 tissue culture medium (Gibco-BRL) containing $5 \%$ fetal bovine serum (Sigma). Follicles were punctured and the cumulus-oocyte complexes removed and placed into acidic L-15 medium (pH 6.0) to obtain cumulus-free oocytes. The oocytes were analyzed either immediately after their isolation or after the indicated times of incubation in a $37^{\circ} \mathrm{C}$ humidified incubator. Growing oocytes did not resume meiosis in vitro, whereas fully grown oocytes were maintained meiotically arrested by their incubation with dbcAMP $(2 \mathrm{mM})$ and the cAMP phosphodiesterase inhibitor IBMX (0.02 mM). Meiotic arrest was identified by the presence of GV. Resumption of meiosis, which was indicated by GVB, occurred spontaneously in oocytes incubated in inhibitor-free medium for $4 \mathrm{~h}$. These oocytes reached $\mathrm{MI}$ at $8 \mathrm{~h}$ after isolation, with PBI being emitted at $10 \mathrm{~h}$ of incubation. Oocytes examined after an overnight incubation were arrested at MII.

\section{Western blot analysis}

At the end of the indicated incubation time, the oocytes were lysed in Laemmli buffer $(125 \mathrm{mM}$ Tris $\mathrm{pH} 6.8,4 \%$ SDS, $10 \%$ glycerol, $0.006 \%$ bromophenol blue, $2 \%$ $\beta$-mercaptoethanol) and the samples were boiled for $5 \mathrm{~min}$. The proteins were electrophoretically separated on a $10 \%$ acrylamide gel, followed by their transfer to a nitrocellulose membrane. After blocking with 5\% skimmed milk, the membranes were incubated with the relevant primary antibodies overnight at $4{ }^{\circ} \mathrm{C}$ followed by the secondary antibodies for $1 \mathrm{~h}$ in room temperature. To confirm the specificity of the signal, the first antibody was preincubated with its relevant peptide $(1: 100)$ for $2 \mathrm{~h}$ at room temperature, prior to immunoblotting. The immunoreactive bands were detected by ECL (Amersham). The intensity of the signal was quantitated by computerized densitometry (quantity one).

\section{Immunocytochemistry}

Oocytes were fixed by $3 \%$ paraformaldehyde for $20 \mathrm{~min}$, followed by their permeabilization with $1 \%$ triton (Sigma) for $4 \mathrm{~min}$. These oocytes were incubated with monoclonal anti-cdc25B (1:200 dilution) at $4{ }^{\circ} \mathrm{C}$, followed by further incubation with the secondary Cy3-conjugated anti-mouse antibody (1:300 dilution) for $1 \mathrm{~h}$ at room temperature. For fluorescent staining of the DNA, syto-13 was added along with the secondary antibody (1:1000). To confirm their specificity, the anticdc25B antibodies were preincubated with the relevant peptide (1:100) for $2 \mathrm{~h}$ at room temperature. All washes were done in GB-PBS (PBS containing $10 \mathrm{mg} / \mathrm{ml}$ of BSA and $10 \mathrm{mM}$ glycine, $\mathrm{pH}$ 7.4). The oocytes were visualized by a laser scanning confocal system (BioRad) attached to an inverted microscope ECLIPSE TE-300 (Nikon; Melville, NY, USA).

\section{Polyadenylation}

The polyadenylation test (PAT) was preformed as described previously (Salles et al. 1999). Briefly, total RNA from 20 oocytes was extracted and dissolved in $5 \mu \mathrm{l}$ double distilled water (DDW). Upon the addition of $1 \mu \mathrm{l}$ of oligo(dt)-anchor $(200 \mathrm{ng} / \mu \mathrm{l}$, $5^{\prime}$-GCGAGCTCCGCGGCCGCGT $12^{-}-3^{\prime}$ ), the test tubes were warmed for $5 \mathrm{~min}$ at $65{ }^{\circ} \mathrm{C}$, and immediately transferred to $42^{\circ} \mathrm{C}$ for $2 \mathrm{~min}$. This was followed by the addition of $14 \mu \mathrm{l}$ of the reverse transcriptase (RT) cocktail [ $4 \mu$ l of $5 \times$ superscript RNase $H^{-}$RT buffer Gibco BRL); $2 \mu \mathrm{l}$ of $0.1 \mathrm{M} \mathrm{DTT} ; 1 \mu \mathrm{l}$ of $10 \mathrm{mM}$ dNTPs; $1 \mu \mathrm{l}$ of RNasin (Promega), $4 \mu \mathrm{l}$ of $\mathrm{H}_{2} \mathrm{O}, 2 \mu \mathrm{l}(200 \mathrm{U} / \mu \mathrm{l})$ superscript RNase $\mathrm{H}^{-} \mathrm{RT}$ (Gibco-BRL)]. The samples were incubated at $42^{\circ} \mathrm{C}$ for $1 \mathrm{~h}$ and kept at $65^{\circ} \mathrm{C}$ for $15 \mathrm{~min}$ for RT inactivation. For the PCR, $1.2 \mu \mathrm{l}$ of cDNAs was added to a $50 \mu \mathrm{l}$ of standard PCR cocktail containing $0.5 \mu \mathrm{l}\left[\alpha-\mathrm{P}^{32}\right]$ dATP and 25 pmol of each cdc25B mRNA specific primer (5'-CTTTTCCTTTAAGACCCCCAG-3') and the oligo(dt)anchor primer (amplification conditions: $93^{\circ} \mathrm{C}$ for $5 \mathrm{~min}$; 30 cycles at $93^{\circ} \mathrm{C}$ for $30 \mathrm{~s} ; 57^{\circ} \mathrm{C}$ for $1 \mathrm{~min} ; 72^{\circ} \mathrm{C}$ for $1 \mathrm{~min}$; with a final extension of $7 \mathrm{~min}$ at $72^{\circ} \mathrm{C}$ ). After amplification, PCR products were ethanol-precipitated with $2.5 \mathrm{M}$ ammonium acetate to remove unincorporated radioactivity. To confirm the specificity of the amplification, samples were digested by the restriction enzyme, Btsl (Promega). The radioactive products were 
electrophoretically separated on 5\% non-denaturing polyacrylamide gel in 0.5X TBE buffer. Gels were dried and radioactivity was determined by their exposure to X-ray film over night.

\section{Microinjection}

For microinjection, the oocytes were placed in a $50 \mu \mathrm{l}$ drop of L-15 tissue culture medium containing dbcAMP (2 mM) and IBMX (0.02 mM), under Paraffin oil. Oocyte were microinjected by 5-7 pl of anti-cdc25B or anti-cdc25C antibodies $(83 \mu \mathrm{g} / \mathrm{ml}$ in $75 \%$ PBS). After microinjection, the oocytes were transferred into inhibitor-free medium, further incubated for $8 \mathrm{~h}$ at $37^{\circ} \mathrm{C}$ and monitored for GVB by differential interference contrast (DIC) microscopy (Zeiss, Germany). Oocytes microinjected with anti-IgG $(83 \mu \mathrm{g} / \mathrm{ml}$ in $75 \%$ PBS) served as control.

\section{Statistical analysis}

The data presented represent an average of the indicated number of individual experiments and are expressed as means \pm s.E.M. Values were compared by F-test and considered statistically different when $P<0.02$.

\section{Results}

\section{Anti-cdc25B, but not anti-cdc25C inhibits GVB}

As mentioned previously, the fertility of mice lacking cdc25C was not impaired. Moreover, the phosphorylation/dephosphorylation status of p34cdc2 in oocytes of these mutant mice throughout meiosis was not different from that in oocytes of wild type mice (Chen et al. 2001). The dispensability of cdc25C is also suggested herein by the failure of neutralizing antibodies of this isoform to interfere with meiosis upon their microinjection into rat oocytes (Fig. 1). On the other hand, microinjection of cdc25B antibodies did inhibit GVB that is the first morphological marker of reinitiation of meiosis. As expected, a large fraction $(77.1 \pm 8.55 \%)$ of control, non-injected oocytes resumed meiosis spontaneously. A slightly but not significantly $(P<0.05)$ lower fraction of anti-IgG-injected oocytes lost their GV throughout $8 \mathrm{~h}$ of incubation $(67.95 \pm 11.24 \%)$. On the other hand, microinjection of anti-cdc25B antibodies significantly $(P<0.02)$ affected the ability of the oocytes to reinitiate meiosis $(G V B=44.96 \pm 8.65 \%)$.

\section{Periodic accumulation of $c d c 25 B$ during meiosis}

Possible modulation of cdc25B activity throughout meiosis was studied at the translational and posttranslational levels. Western blot analysis revealed that cdc25B is expressed by growing, meiotically incompetent oocytes, and that its abundance did not change with oocyte growth (Fig. 2a-b). On the other hand, in fully

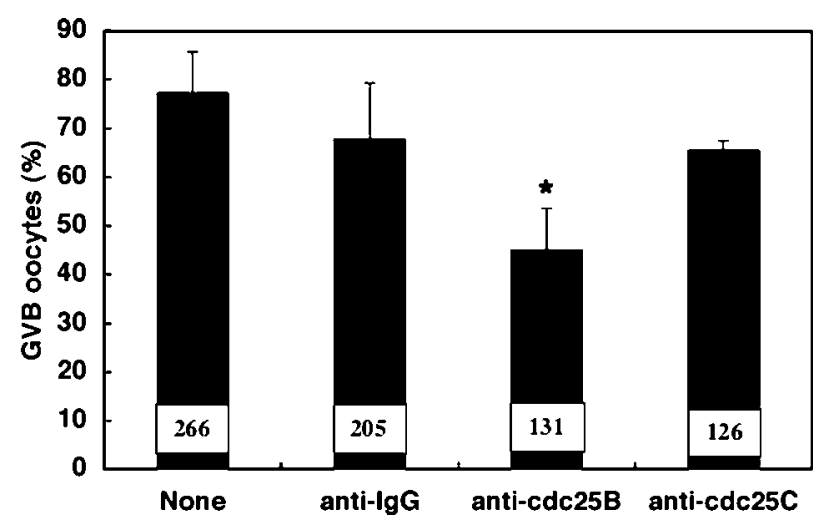

Figure 1 Reinitiation of meiosis in oocytes microinjected with anti-cdc25 antibodies. Oocytes incubated in medium containing dbcAMP in order to maintain them meiotically arrested, were microinjected with either anticdc25B or anti-cdc25C antibodies. After microinjection the oocytes were transferred into dbcAMP-free medium for $8 \mathrm{~h}$ and monitored for GVB. As a control anti-lgG antibodies were injected. Non-injected control oocytes that resume meiosis spontaneously were also included. The means \pm s.E.M. of GVB oocytes obtained in three experiments were calculated.

Statistically significant $(P<0.02)$ differences are marked by $(*)$. Statistical analysis was done using EXCEL. The number of oocytes examined for each point is indicated at the bottom of each column.

grown oocytes, that reinitiate meiosis a unique oscillatory pattern of cdc25B expression is demonstrated as follows. The amount of cdc25B that is elevated at GVB, decreased substantially at $\mathrm{MI}$, followed by a later increase of the enzyme at MII (Fig. 2a-b). At all the developmental stages examined, the oocytes expressed one single protein that was recognized by the anticdc25B antibodies. Incubation of the antibodies with the relevant peptide eliminated immunoreactivity towards this protein indicating specificity towards cdc25B (Fig. 2c). Taken together, these results suggest that cdc25B action throughout meiosis is regulated by modulation of its availability rather than phosphorylation of this enzyme.

The fact that cdc25B was almost absent at MI suggested that this enzyme may be degraded in oocytes at this stage of meiosis. Examining this possibility, we found that incubation of oocytes with the specific proteasome inhibitor, MG132 $(10 \mu \mathrm{M})$, but not the lysosome inhibitor, leupeptin $(5 \mu \mathrm{M})$, blocked the disappearance of cdc25B at $\mathrm{MI}$ (Fig. 3a). These concentrations of the inhibitors have been shown previously to elicit maximal effect in our oocyte system (Josefsberg et al. 2000). These findings indicate that $\mathrm{cdc} 25 \mathrm{~B}$ is degraded at $\mathrm{MI}$ by the proteasome, but not by the lysosome. Using GAP in the Analysis package Wisconsin sequence GCG software we indeed identified the presence of KEN, a domain that is required for proteasome catalyzed proteolysis (Pfleger \& Kirschner 2000), in the molecule of cdc25B. 


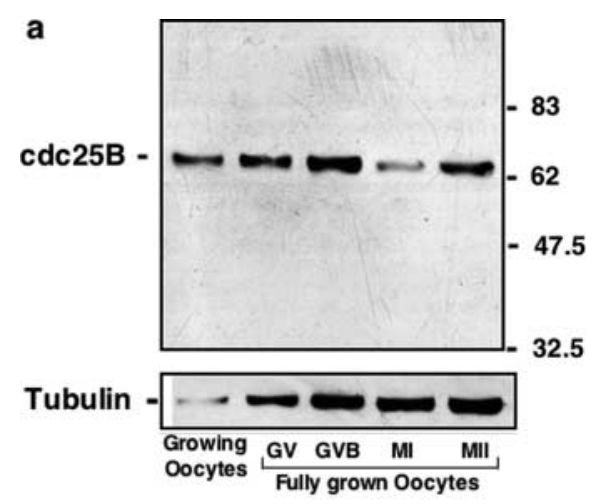

b

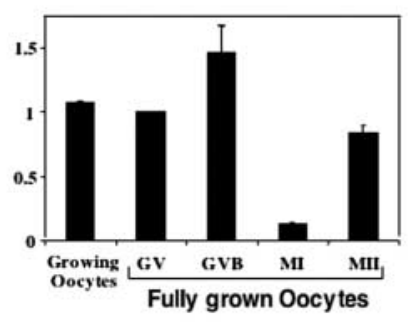

C

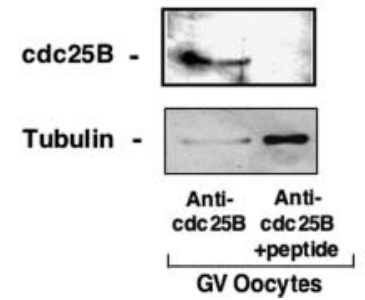

Figure 2 Expression of cdc25B in rat oocytes resuming meiosis: (a) oocytes at different stages of meiosis were extracted and their proteins separated by SDS-PAGE (350 oocytes/lane) followed by immunoblotting with anti-cdc25B antibodies. The results of one representative experiment are presented; (b) quantitation of four independent experiments with similar results; (c) incubation of the antibody with its relevant peptide eliminated immunoreactivity indicating specificity towards cdc25B.

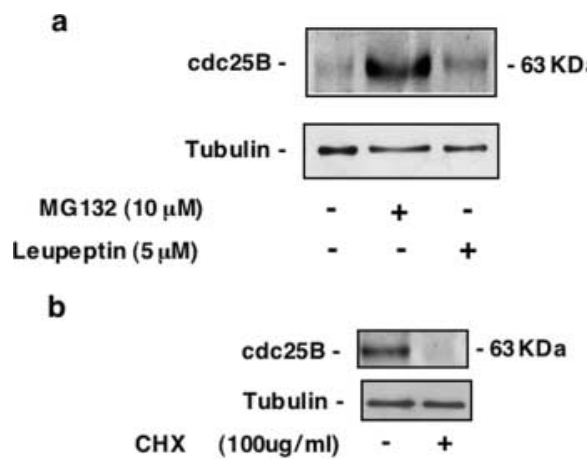

Figure 3 Regulation of cdc25B expression in rat oocyte. Oocytes incubated for the indicated periods of time, were extracted and their proteins separated by SDS-PAGE (400 oocytes/lane) followed by immunoblotting with anti-cdc25B antibodies: (a) oocytes were incubated for $8 \mathrm{~h}$ with MG132, a specific proteasomal inhibitor, or leupeptin, a lysosomal inhibitor; (b) oocytes were incubated for $8 \mathrm{~h}$ to reach $\mathrm{MI}$. $\mathrm{CHX}$ was added and the oocytes were further incubated for additional $16 \mathrm{~h}$. The experiments were repeated three times; the results of one representative experiment are presented.

\section{Translational regulation of cdc $25 B$ involves cytoplasmic polyadenylation}

In order to test whether the elevation of cdc25B at MII, is regulated by translation, oocytes were incubated for $8 \mathrm{~h}$ to allow their progress to $\mathrm{MI}$ of meiosis. At this time point, the protein synthesis inhibitor, cyclohexamide (CHX) was added, and the oocytes were examined for the presence of cdc25B after an additional $20 \mathrm{~h}$. As shown in Fig. 3b, CHX blocked the reappearance of cdc25B at MII. This finding raised the possibility that the accumulation of cdc25B at MII can represent its translational regulation.

Fully grown oocytes that resume meiosis are transcriptionally dormant. These oocytes contain a pool of mRNA, some of which will be eventually translated. The translation of a selective preexiting mRNA is controlled by elongation of its polyA tail (Colgan \& Manley 1997). For further confirmation of translational regulation, oocytes at different stages of meiosis were tested for their cdc25B mRNA polyadenylation. This experiment indeed revealed changes in the length of the cdc25B mRNA polyA tail that coincided with the modifications in the abundance of its protein product demonstrated in this study. Specifically, the GV oocytes possessed a short polyA tail that underwent elongation at GVB. The polyA tail of cdc25B mRNA was short again at MI, with another round of its elongation demonstrated at MII (Fig. 4a). No polyadenylation product was detected in the control samples that were not subjected to RT (data not shown). In order to prove specificity, the polyA samples were subjected to digestion by the restriction enzyme Btsl. The decrease in the size of the reaction product after digestion by $60 \mathrm{bp}$, confirmed its identity as cdc25B mRNA (Fig. 4b).

As previously mentioned by Colgan \& Manley (1997), elongation of the polyA tail of a selective mRNA in oocytes is a perquisite for its translation. In order to confirm that cytoplasmic polyadenylation of the cdc25B, mRNA indeed mediates the synthesis of its corresponding protein, we interfered with this reaction by the use of cordycepin (Rose et al. 1977). As shown in Fig. 4c, oocytes incubated in the presence of cordycepin failed to exhibit the elevated expression of cdc25B demonstrated in oocytes incubated in the absence of this inhibitor. This experiment demonstrates the absolute dependency of cdc25B accumulation on cytoplasmic polyadenylation further confirming our suggestion that the expression of this protein is regulated at the level of translation.

\section{Translocation of cdc25B in oocytes resuming meiosis}

Availability of cdc25B can serve as one mechanism for the control of its activity during meiosis. An additional mode of regulation of the catalytic activity of this enzyme could be possibly provided by its subcellular 
a

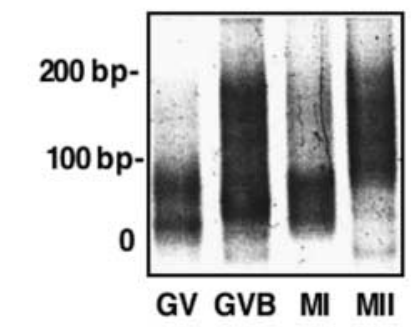

b
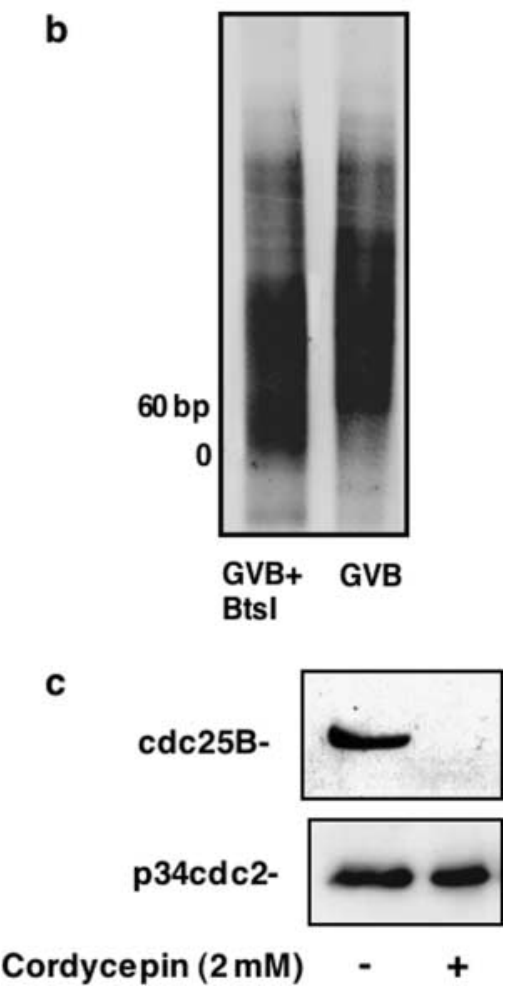

Figure 4 Polyadenylation of cdc25B mRNA in rat oocytes resuming meiosis: (a) total RNA was extracted from oocytes at different stages of meiosis, and the PAT, described in Materials and Methods, was preformed; (b) total RNA was extracted from oocytes at GVB stage, and the PAT test was preformed. The polyA samples were subjected to digestion by the restriction enzyme Btsl; (c) oocytes were incubated for $8 \mathrm{~h}$ to reach MI. Cordycepin was added and the oocytes were further incubated for an additional $16 \mathrm{~h}$. The oocytes were subjected to Western blot analysis as described in Fig. 3. The experiment was repeated three times; the results of one representative experiment are presented.

translocation. To examine this possibility changes in cdc25B localization during resumption of meiosis were monitored by immunostaining. We found that in meiotically arrested oocytes (Fig. 5a A, B) cdc25B is present in the cytoplasm and is absent in the nucleus (Fig. 5a C). After GVB (Fig. 5a E, F) cdc25B migrates towards the condensed chromosomes (Fig. 5a G). Oocytes arrested at MII (Fig. 5a I, J) exhibit low cytoplasmic abundance of cdc25B and co-localization of this protein with the MII spindle apparatus (Fig. 5a K). Preincubation of the antibody with the relevant peptide, abolished the staining, indicating its specificity towards cdc25B (Fig. 5b).

\section{Discussion}

Our findings demonstrate an inhibitory effect of neutralizing cdc25B antibodies on reinitiation of meiosis, further presenting changes in cdc25B localization in rat oocytes resuming meiosis. We also reveal a translationally regulated periodical accumulation of cdc25B that corresponds with the oscillatory pattern of MPF activity throughout meiosis. We show herein that cdc25B translation is mediated by polyadenylation of its mRNA. Taken together, our findings confirm the central role of cdc25B in the control of meiosis in rodent oocytes. They further suggest that temporally and spatially regulated-availability of this phosphatase may coordinate its activity.

The first clue linking cdc25 to the control of cell cycle was provided by observations that a G2-arrest in fission yeast is caused by cdc $25^{-}$mutations (Fantes 1981). Later studies in fission yeast showed that the level of cdc25 mRNA oscillates through the cell cycle, reaching maximum at mitosis (Moreno et al. 1989, Ducommun et al. 1990). These studies raised the idea that periodic accumulation of the cdc25 protein is one of the ratelimiting processes regulating the transition into M-phase. Other studies demonstrated that inactivation of cdc25 results in a late G2-arrest that is accompanied by p34cdc2 phosphorylation (Gould \& Nurse 1989). These and later demonstrations that cdc25 function is not required in strains expressing non-phosphorylatable p34cdc2 (Gould et al. 1990) were consistent with the idea that cdc25 functions to dephosphorylate this kinase.

The information generated in yeast on the role of cdc25 in regulating mitosis has been confirmed for the control of cell division in higher organisms (Sadhu et al. 1990, Gautier et al. 1991). Furthermore, studies in Xenopus oocytes disclosed a similar function for this enzyme in the control of meiosis (Izumi et al. 1992, Jessus \& Beach 1992, Rime et al. 1994). On the other hand, hardly any information has been generated regarding cdc25 in mammalian oocytes. Since mammals express multiple cdc25 genes (Sadhu et al. 1990, Galaktionov \& Beach 1991, Millar et al. 1991, Nagata et al. 1991) the identity of the specific isoform responsible for $\mathrm{p} 34 \mathrm{cdc} 2$ dephosphorylation in mammalian oocytes resuming meiosis raised an additional point of interest.

As mentioned previously, it was commonly accepted that in mammals it is the cdc25C isoform that regulates the exit from G2 and entry into M-phase of the cell cycle (Gautier et al. 1991, Millar et al. 1991). Since reinitiation of meiosis represents a G2- to M-transition, the logical assumption was that resumption of meiosis in mammalian oocytes is subjected to regulation by cdc25C. However, the observation that knockout mice, lacking 
a

DNA

cdc25B

merged

b

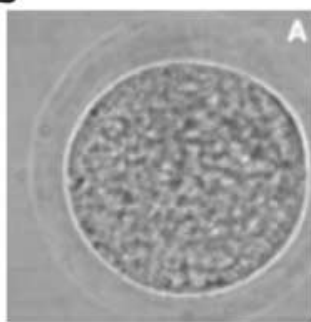

MII
GV
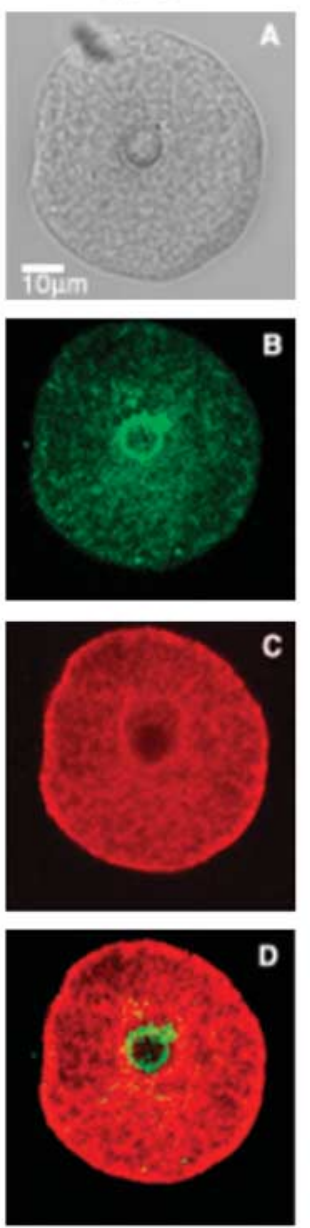

D

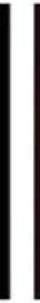

GVB
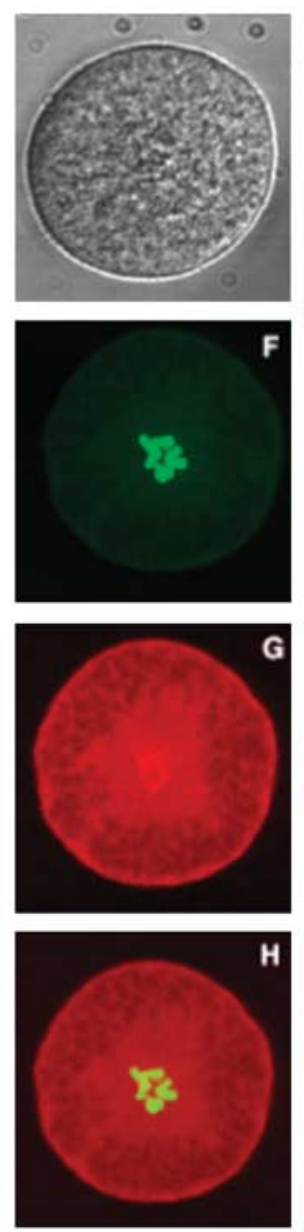

MII
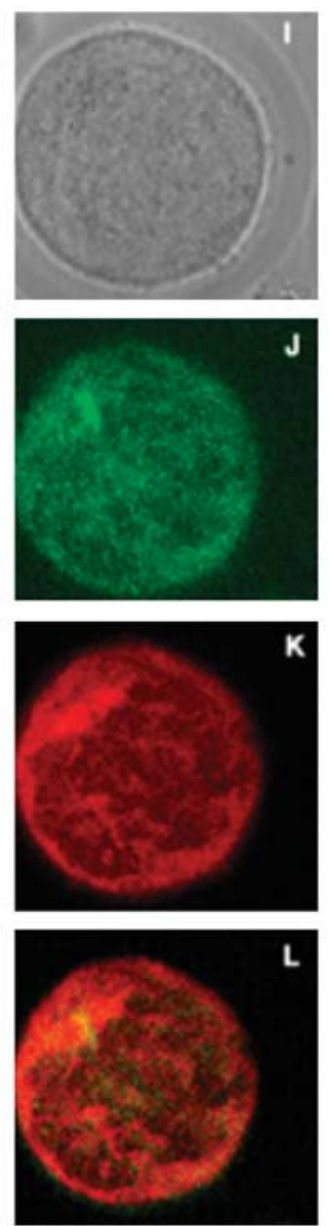

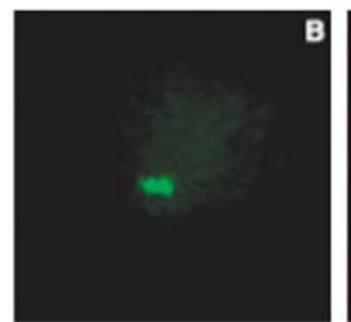

DNA

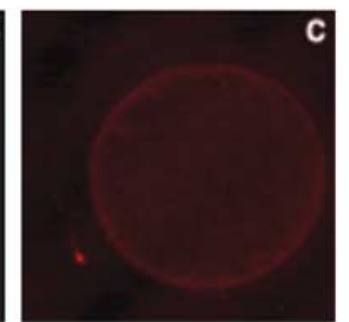

cdc25B

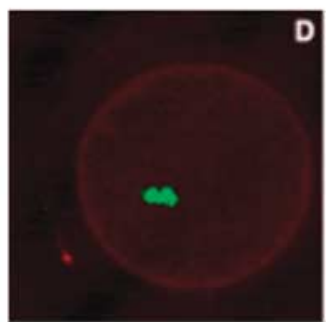

merged +peptide

Figure 5 (a) Translocation of cdc25B in rat oocytes resuming meiosis. Spontaneously maturing oocytes fixed at various stages of meiosis, were immunoreacted with anti-cdc25B antibodies (red) and exposed to syto 13 for DNA staining (green). A meiotically arrested oocyte (A) characterized by the presence of GV (B) showing cytoplasmatic localization of cdc25B (C) and its absence in the nucleus. An oocyte incubated for $6 \mathrm{~h}(\mathrm{E})$, the nuclear membrane of which has disassembled and the chromosomes are condensed (F) shows migration of cdc25B to the chromosomes (G). An oocyte arrested at MII (I), with the chromosomes aligned on the metaphase plate (J), displays translocation of cdc25B to the spindle apparatus (K). The staining for cdc25C (red) and DNA (green) visualized together (D, H, L); (b) Preincubation of the cdc25B antibody with the relevant peptide abolished the staining in MII oocytes, indicating its specificity towards cdc25B (A-C). 
cdc25C, were fertile (Chen et al. 2001) denied a role for this isoform in regulation of meiosis.

The candidacy of cdc25B in regulating reinitiation of meiosis was initially postulated by demonstrations that microinjection of this isoform into Xenopus oocytes induced GVB (Powers et al. 2000). A more recent study showing that oocytes of female mice lacking cdc25B fail to activate MPF and remain meiotically arrested, confirmed this idea (Lincoln et al. 2002). The inhibitory effect of anti-cdc25B and not anti-cdc25C antibodies on reinitiation of meiosis demonstrated herein agrees with the notion that it is the B isoform of the cdc25 phosphatase family that plays a role in reinitiation of meiosis in rat oocytes. These results further suggest that cdc25B and cdc25C do not have redundant roles in regulating meiosis resumption. In fact, some supporting evidence of the role of cdc25B in entry into M-phase has also been generated in mitotically dividing cells. These studies demonstrated that injection of specific antibodies into human fibroblasts or overexpression of cdc25B mutants in HeLa cells inhibit entry into mitosis (Gabrielli et al. 1996, Lammer et al. 1998). Another study showed that overexpression of cdc25B in HeLa cells causes premature transition into M-phase (Karlsson et al. 1999).

A complementary evidence for the role of cdc25B in regulation of oocyte meiosis is provided by the oscillatory pattern of its expression. Cell cycle associated modulation of the expression of cdc25B has been previously reported in mitosis (Russell \& Nurse 1986, Gabrielli et al. 1996, 1997a, Lammer et al. 1998). However, regulation of cdc25 by modulating its availability in the meiotic cell cycle is demonstrated herein. We show that the abundance of this enzyme substantially increases at GVB, transiently decreases at $\mathrm{MI}$ and is elevated again at MII. This periodic accumulation of cdc25B nicely corresponds to the kinetics of MPF activity throughout meiosis (Doree et al. 1983, Hashimoto \& Kishimoto 1986, Choi et al. 1991, Fulka et al. 1992, Josefsberg et al. 2003). It is therefore plausible that the activity of MPF in rat oocytes is controlled by the availability of cdc25B. Accumulation of cdc25B shown herein represents apparently de novo synthesis of the enzyme mediated by polyadenylation.

Fully grown oocytes that resume meiosis are transcriptionally dormant. Protein synthesis in these oocytes is enhanced by recruitment of pooled mRNA and its selective cytoplasmic polyadenylation (Colgan \& Manley 1997). So far, mRNAs for Mos, tPA, cyclin A1 and B1 as well as wee1 (Huarte et al. 1987, Gebauer et al. 1994, Sheets et al. 1994, Stebbins-Boaz et al. 1996, Charlesworth et al. 2000) have been shown to undergo polyadenylation throughout meiosis. We demonstrate herein for the first time that similar to the abovementioned proteins, cdc25B translation in oocytes resuming meiosis is also regulated by its mRNA polyadenylation. Identification of both $\mathrm{CPE}$ and hexanucleotide sequence in the cdc25B mRNA agrees with our finding. Unlike the above-mentioned mRNAs, that exhibit an elongated polyA tail soon after reinitiation of meiosis that sustains throughout meiosis (Sheets et al. 1994, de Moor \& Richter 1997, Lazar et al. 2002), polyadenylation of cdc25B mRNA and the subsequent accumulation of its protein product exhibits an oscillatory pattern.

It has been shown in Xenopus oocytes that polyadenylation of cyclin B and cyclin A mRNAs is Mosdependent and that this effect of Mos is mediated by MPF (de Moor \& Richter 1997). A later study in the rat revealed that Mos mRNA polyadenylation is subjected to negative regulation of CAMP and that this inhibitory effect is mediated by PKA (Lazar et al. 2002). A more recent report further demonstrated that Mos mRNA polyadenylation in rat oocytes will not take place in absence of an active MPF (Lazar et al. 2004). The mechanisms that regulate cdc25B expression during oocyte maturation remain to be elucidated.

The cdc25B mRNA polyadenylation followed by its translation in GVB oocytes, nicely corresponds with MPF activation at reinitiation of meiosis. However, the reduction in the amount of cdc25B at $\mathrm{MI}$ is somewhat unexpected, since inactivation of MPF upon completion of the first meiotic division that is subsequent to cyclin degradation, is not associated with p34cdc2 rephosphorylation (Choi et al. 1991, Goren \& Dekel 1994). Furthermore, since reactivation of MPF upon the transition into MII is supposed to be solely dependent on cyclin synthesis, the second round of cdc25B mRNA polyadenylation was not anticipated. A clue for the possible role for cdc25B accumulation after completion of the first meiotic division is provided by a recent demonstration that co-expression of cdc25B and cyclin $B$ in $\mathrm{G} 1$ cells drives the cells to enter mitosis without DNA replication (Karlsson et al. 1999). The concomitant elevation of cdc25B and cyclin B upon transition into MII may provide the mechanism that uncouples between cell division and DNA replication causing two sequential M-phases in meiosis. In addition, a previous study (Nakajo et al. 2000) claimed that wee1 decreases after reinitiation of meiosis and remains low until fertilization. Indeed, in the absence of wee1, there is no requirement for cdc25 to balance its effect on p34cdc2 phosphorylation. However, another report demonstrating that wee1 is present in oocytes resuming meiosis (Iwabuchi et al. 2000) disagrees with this idea further suggesting that accumulation of cdc25B may have a role in MPF reactivation at the entry into the second meiotic division.

The periodic pattern of cdc25B accumulation demonstrated herein in rat oocytes throughout meiosis is regulated by protein synthesis and apparently balanced by proteasomal degradation. Proteolysis of cdc25B that is brought about by the proteasome has been previously demonstrated (Baldin etal. 1997a, Cans et al. 1999). It has also been reported that at least in yeast cdc 25 degradation is preceded by its ubiquitination (Nefsky \& Beach 1996). 
This study further identified pub1, a major ubiquitin ligase of cdc25, the disruption of which dramatically reduces ubiquitination of cdc25 further stimulating premature entry into mitosis. Along this line, we report herein that the KEN motif, a domain on the molecule required for ubiquitin-mediated proteolysis (Pfleger \& Kirschner 2000) can be identified in the cdc25B molecule.

Regulation of cdc25B by synthesis and degradation could be modulated by subcellular localization restricting its function to a precise cellular location. In support of this idea, a cell cycle-dependent transport of cdc25B in and out the nucleus, has been demonstrated in somatic (Girard et al. 1992, Garner-Hamrick \& Fisher 1998, Dalal et al. 1999, Davezac et al. 2000). Our immunocytochemical experiments revealed a restricted cytoplasmatic localization of cdc25B in G2-arrested oocytes. We further demonstrate herein that cdc25B co-localizes with the spindle apparatus, which is of most interest. It has been shown that cyclin B and cdc25B translocate to the nucleus in concert (Gabrielli et al. 1996, 1997 b) and that the cytoplasmatic localization of cdc25B depends upon cyclin B (Karlsson et al. 1999). Since cyclin B has also been demonstrated to be associated with the meiotic spindle (our unpublished observations), these findings may represent compartmentalization of the enzyme and its substrate that increases the efficiency of its catalytic activity. Finally, another support to this idea is provided by a recent study demonstrating that cdc25B has a role in activating the cyclin B-Cdk1 complex on the centrosomes at the G2/M transition in Hela cells undergoing mitosis (Lindqvist et al. 2005). In summary, our findings not only confirm the role of cdc25B in rodent oocytes, but also present a unique mode of regulation of the activity of this phosphatase by temporal and spatial modulation of its availability.

\section{Acknowledgements}

We thank Drs Irit Granot and Ahuva Knyszynski for oocytes microinjection. This work was supported by a research grant from the Dwek Fund for the Biomedical Research. N Dekel is incumbent of the Phillip M Klutznick professional chair for Developmental Biology. The authors declare that there is no conflict of interest that would prejudice the impartiality of this Scientific work.

\section{References}

Alphey L, Jimenez J, White-Cooper H, Dawson I, Nurse P \& Glover DM 1992 twine, a cdc25 homolog that functions in the male and female germline of Drosophila. Cell 69 977-988.

Ashcroft NR, Kosinski ME, Wickramasinghe D, Donovan PJ \& Golden A 1998 The four cdc25 genes from the nematode Caenorhabditis elegans. Gene 214 59-66.

Baldin V, Cans C, Knibiehler M \& Ducommun B 1997a Phosphorylation of human CDC25B phosphatase by CDK1-cyclin A triggers its proteasome-dependent degradation. Journal of Biological Chemistry 272 32731-32734.
Baldin V, Cans C, Superti-Furga G \& Ducommun B 1997b Alternative splicing of the human CDC25B tyrosine phosphatase, Possible implications for growth control? Oncogene 14 2485-2495.

Booher RN, Holman PS \& Fattaey A 1997 Human Myt1 is a cell cycleregulated kinase that inhibits $\mathrm{Cdc} 2$ but not Cdk2 activity. Journal of Biological Chemistry 272 22300-22306.

Cans C, Ducommun B \& Baldin V 1999 Proteasome-dependent degradation of human CDC25B phosphatase. Molecular Biology Reports 26 53-57.

Charlesworth A, Welk J \& MacNicol AM 2000 The temporal control of Wee1 mRNA translation during Xenopus oocyte maturation is regulated by cytoplasmic polyadenylation elements within the 3'-untranslated region. Developmental Biology 227 706-719.

Chen MS, Hurov J, White LS, Woodford-Thomas T \& Piwnica-Worms H 2001 Absence of apparent phenotype in mice lacking Cdc25C protein phosphatase. Molecular and Cellular Biology 21 3853-3861.

Choi T, Aoki F, Mori M, Yamashita M, Nagahama Y \& Kohmoto K 1991 Activation of p34cdc2 protein kinase activity in meiotic and mitotic cell cycles in mouse oocytes and embryos. Development 113 789-795.

Clarke PR, Hoffmann I, Draetta G \& Karsenti E 1993 Dephosphorylation of cdc25-C by a type-2A protein phosphatase: specific regulation during the cell cycle in Xenopus egg extracts. Molecular Biology of the Cell 4 397-411.

Colgan DF \& Manley JL 1997 Mechanism and regulation of mRNA polyadenylation. Genes \& Development 11 2755-2766.

Conklin DS, Galaktionov K \& Beach D 1995 14-3-3 proteins associate with cdc25 phosphatases. PNAS 92 7892-7896.

Courtot C, Fankhauser C, Simanis V \& Lehner CF 1992 The Drosophila cdc25 homolog twine is required for meiosis. Development $\mathbf{1 1 6}$ 405-416.

Dai Y, Lee C, Hutchings A, Sun Y \& Moor R 2000 Selective requirement for $\mathrm{Cdc} 25 \mathrm{C}$ protein synthesis during meiotic progression in porcine oocytes. Biology of Reproduction 62 519-532.

Dalal SN, Schweitzer CM, Gan J \& DeCaprio JA 1999 Cytoplasmic localization of human cdc25C during interphase requires an intact 14-3-3 binding site. Molecular and Cellular Biology 19 4465-4479.

Davezac N, Baldin V, Gabrielli B, Forrest A, Theis-Febvre N, Yashida M \& Ducommun B 2000 Regulation of CDC25B phosphatases subcellular localization. Oncogene 19 2179-2185.

de Moor CH \& Richter JD 1997 The Mos pathway regulates cytoplasmic polyadenylation in Xenopus oocytes. Molecular and Cellular Biology 17 6419-6426.

Dekel N 1996 Protein phosphorylation/dephosphorylation in the meiotic cell cycle of mammalian oocytes. Reviews of Reproduction 1 82-88.

Doree M, Peaucellier G \& Picard A 1983 Activity of the maturationpromoting factor and the extent of protein phosphorylation oscillate simultaneously during meiotic maturation of starfish oocytes. Developmental Biology 99 489-501.

Ducommun B, Draetta G, Young P \& Beach D 1990 Fission yeast cdc25 is a cell-cycle regulated protein. Biochemical and Biophysical Research Communications 167 301-309.

Edgar BA \& O'Farrell PH 1989 Genetic control of cell division patterns in the Drosophila embryo. Cell 57 177-187.

Fantes PA 1981 Isolation of cell size mutants of a fission yeast by a new selective method: characterization of mutants and implications for division control mechanisms. Journal of Bacteriology 146 746-754.

Fulka J Jr, Jung T \& Moor RM 1992 The fall of biological maturation promoting factor (MPF) and histone $\mathrm{H} 1$ kinase activity during anaphase and telophase in mouse oocytes. Molecular Reproduction and Development 32 378-382.

Furnari B, Rhind N \& Russell P 1997 Cdc25 mitotic inducer targeted by chk1 DNA damage checkpoint kinase. Science 277 1495-1497.

Gabrielli BG, Clark JM, McCormack AK \& Ellem KA 1997a Hyperphosphorylation of the $\mathrm{N}$-terminal domain of $\mathrm{Cdc} 25$ regulates activity toward cyclin B1/Cdc2 but not cyclin A/Cdk2. Journal of Biological Chemistry 272 28607-28614. 
Gabrielli BG, Clark JM, McCormack AK \& Ellem KA 1997b Ultraviolet light-induced G2 phase cell cycle checkpoint blocks cdc25dependent progression into mitosis. Oncogene 15 749-758.

Gabrielli BG, De Souza CP, Tonks ID, Clark JM, Hayward NK \& Ellem KA 1996 Cytoplasmic accumulation of cdc25B phosphatase in mitosis triggers centrosomal microtubule nucleation in HeLa cells. Journal of Cell Science 109 1081-1093.

Galaktionov K \& Beach D 1991 Specific activation of cdc25 tyrosine phosphatases by B-type cyclins: evidence for multiple roles of mitotic cyclins. Cell 67 1181-1194.

Garner-Hamrick PA \& Fisher C 1998 Antisense phosphorothioate oligonucleotides specifically down-regulate cdc25B causing S-phase delay and persistent antiproliferative effects. International Journal of Cancer 76 720-728.

Gautier J, Minshull J, Lohka M, Glotzer M, Hunt T \& Maller JL 1990 Cyclin is a component of maturation-promoting factor from Xenopus. Cell 60 487-494.

Gautier J, Norbury C, Lohka M, Nurse P \& Maller J 1988 Purified maturation-promoting factor contains the product of a Xenopus homolog of the fission yeast cell cycle control gene cdc $2+$. Cell $\mathbf{5 4}$ 433-439.

Gautier J, Solomon MJ, Booher RN, Bazan JF \& Kirschner MW 1991 cdc25 is a specific tyrosine phosphatase that directly activates p34cdc2. Cell 67 197-211.

Gebauer F, Xu W, Cooper GM \& Richter JD 1994 Translational control by cytoplasmic polyadenylation of c-mos mRNA is necessary for oocyte maturation in the mouse. EMBO Journal 135712.

Girard F, Strausfeld U, Cavadore JC, Russell P, Fernandez A \& Lamb NJ 1992 cdc25 is a nuclear protein expressed constitutively throughout the cell cycle in nontransformed mammalian cells. Journal of Cell Biology 118 785-794.

Goren S \& Dekel N 1994 Maintenance of meiotic arrest by a phosphorylated p34cdc2 is independent of cyclic adenosine $3^{\prime}, 5^{\prime}$ monophosphate. Biology of Reproduction 51 956-962.

Gould KL, Moreno S, Tonks NK \& Nurse P 1990 Complementation of the mitotic activator, p80cdc25, by a human protein-tyrosine phosphatase. Science 250 1573-1576.

Gould KL \& Nurse P 1989 Tyrosine phosphorylation of the fission yeast cdc2 + protein kinase regulates entry into mitosis. Nature 342 39-45.

Hashimoto N \& Kishimoto T 1986 Cell cycle dynamics of maturationpromoting factor during mouse oocyte maturation. Tokai Journal of Experimental and Clinical Medicine 11 471-477.

Hoffmann I, Clarke PR, Marcote MJ, Karsenti E \& Draetta G 1993 Phosphorylation and activation of human cdc25-C by cdc2-cyclin B and its involvement in the self-amplification of MPF at mitosis. EMBO Journal 12 53-63.

Hoffmann I, Draetta G \& Karsenti E 1994 Activation of the phosphatase activity of human cdc25A by a cdk2-cyclin E dependent phosphorylation at the G1/S transition. EMBO Journal 13 4302-4310.

Huarte J, Belin D, Vassalli A, Strickland S \& Vassalli JD 1987 Meiotic maturation of mouse oocytes triggers the translation and polyadenylation of dormant tissue-type plasminogen activator mRNA. Genes \& Development 1 1201-1211.

Iwabuchi M, Ohsumi K, Yamamoto TM, Sawada W \& Kishimoto T 2000 Residual Cdc2 activity remaining at meiosis I exit is essential for meiotic M-M transition in Xenopus oocyte extracts. EMBO Journal 19 4513-4523.

Izumi T, Walker DH \& Maller JL 1992 Periodic changes in phosphorylation of the Xenopus cdc25 phosphatase regulate its activity. Molecular Biology of the Cell 3 927-939.

Jessus C \& Beach D 1992 Oscillation of MPF is accompanied by periodic association between cdc 25 and cdc2-cyclin B. Cell 68 323-332.

Jinno S, Suto K, Nagata A, Igarashi M, Kanaoka Y, Nojima H \& Okayama H 1994 Cdc25A is a novel phosphatase functioning early in the cell cycle. EMBO Journal 13 1549-1556.

Josefsberg LB, Galiani D, Dantes A, Amsterdam A \& Dekel N 2000 The proteasome is involved in the first metaphase-to-anaphase transition of meiosis in rat oocytes. Biology of Reproduction 62 1270-1277.
Josefsberg LB, Galliani D, Lazar S, Kaufman O, Seger R \& Dekel N 2003 Maturation promoting factor govens mitogen-activated protein kinase activation and inter phase suppression during meiosis of rat oocytes. Biology of Reproduction 68 1282-1290.

Karlsson C, Katich S, Hagting A, Hoffmann I \& Pines J 1999 Cdc25B and $\mathrm{Cdc} 25 \mathrm{C}$ differ markedly in their properties as initiators of mitosis. Journal of Cell Biology 146 573-584.

Kumagai A \& Dunphy WG 1991 The cdc25 protein controls tyrosine dephosphorylation of the cdc2 protein in a cell-free system. Cell 64 903-914.

Kumagai A \& Dunphy WG 1992 Regulation of the cdc25 protein during the cell cycle in Xenopus extracts. Cell 70 139-151.

Kumagai A \& Dunphy WG 1996 Purification and molecular cloning of Plx1, a Cdc25-regulatory kinase from Xenopus egg extracts. Science 273 1377-1380.

Kumagai A \& Dunphy WG 1999 Binding of 14-3-3 proteins and nuclear export control the intracellular localization of the mitotic inducer Cdc25. Genes \& Development 13 1067-1072.

Lammer C, Wagerer S, Saffrich R, Mertens D, Ansorge W \& Hoffmann I 1998 The cdc25B phosphatase is essential for the G2/M phase transition in human cells. Journal of Cell Science 111 2445-2453.

Lazar S, Galiani D \& Dekel N 2002 cyclic AMP-dependent protein kinase (PKA) negatively regulates polyadenylation of c-mos mRNA in rat oocytes. Molecular Endocrinology 16 331-341.

Lazar S, Gershon E \& Dekel N 2004 Selective degradation of cyclin B1 mRNA in rat oocytes by RNA interference (RNAi). Journal of Molecular Endocrinology 33 73-85.

Lincoln AJ, Wickramasinghe D, Stein P, Schultz RM, Palko ME, De Miguel MP, Tessarollo L \& Donovan PJ 2002 Cdc25b phosphatase is required for resumption of meiosis during oocyte maturation. Nature Genetics 30 446-449.

Lindqvist A, Kallstrom H, Lundgren A, Barsoum E \& Rosenthal CK 2005 Cdc25B cooperates with Cdc25A to induce mitosis but has a unique role in activating cyclin $\mathrm{B} 1-\mathrm{Cdk} 1$ at the centrosome. Journal of Cell Biology 171 35-45.

Masui Y \& Markert CL 1971 Cytoplasmic control of nuclear behavior during meiotic maturation of frog oocytes. Journal of Experimental Zoology 177 129-145.

Millar JB, Blevitt J, Gerace L, Sadhu K, Featherstone C \& Russell P 1991 p55CDC25 is a nuclear protein required for the initiation of mitosis in human cells. PNAS 88 10500-10504.

Mitra J \& Schultz RM 1996 Regulation of the acquisition of meiotic competence in the mouse: changes in the subcellular localization of cdc2, cyclin B1, cdc25C and wee1, and in the concentration of these proteins and their transcripts. Journal of Cell Science 109 24072415.

Moreno S, Hayles J \& Nurse P 1989 Regulation of p34cdc2 protein kinase during mitosis. Cell 58 361-372.

Mueller PR, Coleman TR, Kumagai A \& Dunphy WG 1995 Myt1: a membrane-associated inhibitory kinase that phosphorylates Cdc2 on both threonine-14 and tyrosine-15. Science 270 86-90.

Nagata A, Igarashi M, Jinno S, Suto K \& Okayama H 1991 An additional homolog of the fission yeast cdc25+ gene occurs in humans and is highly expressed in some cancer cells. New Biology 3 959-968.

Nakajo N, Yoshitome S, Iwashita J, lida M, Uto K, Ueno S, Okamoto K \& Sagata N 2000 Absence of Wee1 ensures the meiotic cell cycle in Xenopus oocytes. Genes \& Development 14 328-338.

Nefsky B \& Beach D 1996 Pub1 acts as an E6-AP-like protein ubiquitiin ligase in the degradation of cdc25. EMBO Journal 15 1301-1312.

Nishijima H, Nishitani H, Seki T \& Nishimoto T 1997 A dual-specificity phosphatase $C \mathrm{Cd} 25 \mathrm{~B}$ is an unstable protein and triggers p34(cdc2) /cyclin B activation in hamster BHK21 cells arrested with hydroxyurea. Journal of Cell Biology 138 1105-1116.

Peng CY, Graves PR, Thoma RS, Wu Z, Shaw AS \& Piwnica-Worms H 1997 Mitotic and G2 checkpoint control: regulation of 14-3-3 protein binding by phosphorylation of Cdc25C on serine-216. Science 277 1501-1505. 
Pfleger CM \& Kirschner MW 2000 The KEN, box: an APC recognition signal distinct from the D box targeted by Cdh1. Genes \& Development 14 655-665.

Powers EA, Thompson DP, Garner-Hamrick PA, He W, Yem AW, Bannow CA, Staples DJ, Waszak GA, Smith CW, Deibel MR Jr \& Fisher C 2000 Identification of a C-terminal cdc25 sequence required for promotion of germinal vesicle breakdown. The Biochemical Journal 347 653-660.

Qian YW, Erikson E \& Maller JL 1998 Purification and cloning of a protein kinase that phosphorylates and activates the polo-like kinase Plx1. Science 282 1701-1704.

Rime H, Huchon D, De Smedt V, Thibier C, Galaktionov K, Jessus C \& Ozon R 1994 Microinjection of Cdc25 protein phosphatase into Xenopus prophase oocyte activates MPF and arrests meiosis at metaphase I. Biology of the Cell 82 11-22.

Rose KM, Bell LE \& Jacob ST 1977 Selective inhibition of initial polyadenylation in isolated nuclei by low levels of cordycepin 5"-triphosphate. Biochimica et Biophysica Acta 475 548-552.

Russell P, Moreno S \& Reed SI 1989 Conservation of mitotic controls in fission and budding yeasts. Cell 57 295-303.

Russell P \& Nurse P 1986 cdc25 + functions as an inducer in the mitotic control of fission yeast. Cell 45 145-153.

Sadhu K, Reed SI, Richardson H \& Russell P 1990 Human homolog of fission yeast cdc25 mitotic inducer is predominantly expressed in G2. PNAS 87 5139-5143.

Salles FJ, Richards WG \& Strickland S 1999 Assaying the polyadenylation state of mRNAs. Methods 17 38-45.

Sebastian B, Kakizuka A \& Hunter T 1993 Cdc25M2 activation of cyclin-dependent kinases by dephosphorylation of threonine-14 and tyrosine-15. PNAS 90 3521-3524.
Sheets MD, Fox CA, Hunt T, Vande Woude G \& Wickens M 1994 The 3'-untranslated regions of c-mos and cyclin mRNAs stimulate translation by regulating cytoplasmic polyadenylation. Genes \& Development 8 926-938.

Stebbins-Boaz B, Hake LE \& Richter JD 1996 CPEB, controls the cytoplasmic polyadenylation of cyclin, Cdk2 and c-mos mRNAs and is necessary for oocyte maturation in Xenopus. EMBO Journal 15 2582-2592.

Strausfeld U, Labbe JC, Fesquet D, Cavadore JC, Picard A, Sadhu K, Russell P \& Doree M 1991 Dephosphorylation and activation of a p34cdc2/cyclin B complex in vitro by human CDC25 protein. Nature 351 242-245.

Tsafriri A \& Dekel N (Eds) 1994 Molecular mechanisms in ovulation. In Molecular Biology of the Female Reproductive System Academic press.

Wickramasinghe D, Becker S, Ernst MK, Resnick JL, Centanni JM, Tessarollo L, Grabel LB \& Donovan PJ 1995 Two CDC25 homologues are differentially expressed during mouse development. Development 121 2047-2056.

Wu S \& Wolgemuth DJ 1995 The distinct and developmentally regulated patterns of expression of members of the mouse Cdc25 gene family suggest differential functions during gametogenesis. Developmental Biology 170 195-206.

Zeng Y \& Piwnica-Worms H 1999 DNA, damage and replication checkpoints in fission yeast require nuclear exclusion of the $\mathrm{Cdc} 25$ phosphatase via 14-3-3 binding. Molecular and Cellular Biology 19 7410-7419.

Received 29 December 2005

First decision 26 January 2006

Revised manuscript received 10 February 2006

Accepted 14 March 2006 